\title{
Clinical Phenotype of Diabetic Peripheral Neuropathy and Relation to Symptom Patterns: Cluster and Factor Analysis in Patients with Type 2 Diabetes in Korea
}

\author{
Jong Chul Won, ${ }^{1}$ Yong-Jin Im, ${ }^{2}$ Ji-Hyun Lee, ${ }^{3}$ Chong Hwa Kim, ${ }^{4}$ Hyuk Sang Kwon, ${ }^{5}$ \\ Bong-Yun Cha, ${ }^{5}$ and Tae Sun Park ${ }^{6}$ \\ ${ }^{1}$ Department of Internal Medicine, Cardiovascular and Metabolic Disease Center, Inje University, Sanggye Paik Hospital, \\ Inje University School of Medicine, Seoul, Republic of Korea \\ ${ }^{2}$ Clinical Trial Center and Biomedical Research Institute, Chonbuk National University Hospital, Jeonju, Republic of Korea \\ ${ }^{3}$ Department of Internal Medicine, Daegu Catholic University School of Medicine, Daegu, Republic of Korea \\ ${ }^{4}$ Department of Internal Medicine, Sejong General Hospital, Bucheon, Republic of Korea \\ ${ }^{5}$ Department of Internal Medicine, The Catholic University of Korea, School of Medicine, Seoul, Republic of Korea \\ ${ }^{6}$ Department of Internal Medicine Chonbuk National University Medical School, \\ Research Institute of Clinical Medicine Chonbuk National University Hospital, Division of Endocrinology and Metabolism, \\ Jeonju, Republic of Korea
}

Correspondence should be addressed to Tae Sun Park; pts@jbnu.ac.kr

Received 3 May 2017; Revised 19 October 2017; Accepted 8 November 2017; Published 13 December 2017

Academic Editor: Sergiu Catrina

Copyright ( 2017 Jong Chul Won et al. This is an open access article distributed under the Creative Commons Attribution License, which permits unrestricted use, distribution, and reproduction in any medium, provided the original work is properly cited.

\begin{abstract}
Objectives. Patients with diabetic peripheral neuropathy (DPN) is the most common complication. However, patients are usually suffering from not only diverse sensory deficit but also neuropathy-related discomforts. The aim of this study is to identify distinct groups of patients with DPN with respect to its clinical impacts on symptom patterns and comorbidities. Methods. A hierarchical cluster analysis and factor analysis were performed to identify relevant subgroups of patients with DPN $(n=1338)$ and symptom patterns. Results. Patients with DPN were divided into three clusters: asymptomatic (cluster $1, n=448,33.5 \%$ ), moderate symptoms with disturbed sleep (cluster 2, $n=562,42.0 \%$ ), and severe symptoms with decreased quality of life (cluster $3, n=328,24.5 \%)$. Patients in cluster 3, compared with clusters 1 and 2, were characterized by higher levels of HbAlc and more severe pain and physical impairments. Patients in cluster 2 had moderate pain levels but disturbed sleep patterns comparable to those in cluster 3. The frequency of symptoms on each item of MNSI by "painful" symptom pattern showed a similar distribution pattern with increasing intensities along the three clusters. Conclusions. Cluster and factor analysis endorsed the use of comprehensive and symptomatic subgrouping to individualize the evaluation of patients with DPN.
\end{abstract}

\section{Introduction}

Diabetic peripheral neuropathy (DPN) is the most common and earliest complication in patients with type 2 diabetes. Our previous study found that nearly one-third patients with type 2 diabetes have DPN in Korea [1]. DPN is known as progressive damage of various types of nerve fibers, and these resulted in a broad spectrum of symptoms and signs along the course of diabetes. Recently, it is suggested that DPN could be diagnosed by its typical symptom(s) and/or sign(s) in clinical terms [2]. However, DPN is a very heterogeneous disease with differences in perception and recognition sensory symptoms among patients.

Somatic pain caused by diabetes often resulted in complications such as sleep disturbance and decreased QOL. Our previous study reported that the prevalence of painful DPN 
TABLE 1: Comparison of the demographic and clinical characteristics and the clinical impacts of diabetic peripheral neuropathy on pain, sleep, and quality of life in three clustered groups in the entire patients $(n=1338)$.

\begin{tabular}{|c|c|c|c|c|}
\hline Variable & $\begin{array}{l}\text { Cluster } 1 \\
(n=448)\end{array}$ & $\begin{array}{l}\text { Cluster } 2 \\
(n=562)\end{array}$ & $\begin{array}{l}\text { Cluster } 3 \\
(n=328)\end{array}$ & $P$ value \\
\hline Age, years & $61.7 \pm 9.9$ & $62.6 \pm 11.5$ & $62.7 \pm 10.5$ & 0.3058 \\
\hline Female, $n(\%)$ & $202(45.1)^{\int, 9}$ & $345(61.4)$ & $198(60.4)$ & $<0.001$ \\
\hline Diabetes treatment, $n(\%)$ & & & & $<0.001$ \\
\hline Diet and exercise & $14(3.1)^{\int, 9}$ & $4(0.7)^{9}$ & $6(1.8)$ & \\
\hline OHA & $297(66.3)^{\int, 9}$ & $321(57.1)^{9}$ & $143(43.6)$ & \\
\hline Insulin & $40(8.9)^{\int, \boldsymbol{g}}$ & $76(13.5)^{9}$ & $70(21.3)$ & \\
\hline Insulin and OHA & $97(21.7)^{\int, 9}$ & $161(28.7)^{9}$ & $109(33.2)$ & \\
\hline BMI, $\mathrm{kg} / \mathrm{m}^{2}$ & $24.9 \pm 3.4$ & $24.9 \pm 3.5^{9}$ & $25.5 \pm 4.1$ & 0.0394 \\
\hline FPG, mg/dL & $137.8 \pm 44.3^{\int, 9}$ & $141.9 \pm 54.3^{9}$ & $153.0 \pm 71.1$ & 0.0048 \\
\hline $\mathrm{HbA1c}, \%$ & $7.5 \pm 1.3^{\int, 9}$ & $7.8 \pm 1.6^{9}$ & $8.2 \pm 4.0$ & 0.002 \\
\hline $\mathrm{HbAlc}, \mathrm{mmol} / \mathrm{mol}$ & $58.6 \pm 14.6^{\int, 9}$ & $61.3 \pm 17.6^{9}$ & $65.6 \pm 43.5$ & 0.002 \\
\hline Hypertension & $276(61.6)$ & $383(68.15)$ & $220(67.1)$ & 0.0781 \\
\hline Dyslipidemia & $242(54.0)$ & $301(53.6)$ & $161(49.1)$ & 0.334 \\
\hline Obesity & $29(6.5)$ & $33(5.9)$ & $18(5.5)$ & 0.8408 \\
\hline Diabetic retinopathy, $n(\%)$ & $122(27.2)^{\int, 9}$ & $178(31.7)^{9}$ & $125(38.1)$ & 0.0057 \\
\hline Diabetic nephropathy & $83(18.5)^{\int, 9}$ & $133(23.7)^{9}$ & $85(25.9)$ & 0.0353 \\
\hline MNSI score & $1.6 \pm 1.2^{\int, 9}$ & $3.1 \pm 1.7^{9}$ & $5.4 \pm 2.1$ & $<0.001$ \\
\hline \multicolumn{5}{|l|}{ Pain severity items } \\
\hline Worst & $0.39 \pm 1.01^{\int, 9}$ & $3.20 \pm 2.99^{9}$ & $7.04 \pm 2.41$ & $<0.001$ \\
\hline Weakest & $0.03 \pm 0.20^{\int, g}$ & $0.60 \pm 1.03^{5}$ & $2.37 \pm 2.10$ & $<0.001$ \\
\hline Average & $0.14 \pm 0.46^{\int, g}$ & $1.76 \pm 1.78^{9}$ & $4.63 \pm 2.08$ & $<0.001$ \\
\hline \multicolumn{5}{|l|}{ Pain interference items* } \\
\hline General activity & $0.10 \pm 0.47^{\int, g}$ & $1.23 \pm 2.19^{9}$ & $4.96 \pm 3.24$ & $<0.001$ \\
\hline Mood & $0.21 \pm 0.91^{\int, 9}$ & $1.82 \pm 2.53^{9}$ & $5.63 \pm 3.10$ & $<0.001$ \\
\hline Walking & $0.09 \pm 0.51^{\int, 9}$ & $1.06 \pm 2.16^{9}$ & $4.82 \pm 3.29$ & $<0.001$ \\
\hline Normal work & $0.08 \pm 0.56^{\int, 9}$ & $1.10 \pm 2.13^{5}$ & $4.73 \pm 3.35$ & $<0.001$ \\
\hline Relationship & $0.04 \pm 0.31^{\int, 9}$ & $0.54 \pm 1.45^{9}$ & $3.07 \pm 3.38$ & $<0.001$ \\
\hline Sleep & $0.13 \pm 0.60^{\int, 9}$ & $1.52 \pm 2.57^{9}$ & $4.22 \pm 3.59$ & $<0.001$ \\
\hline Enjoyment of life & $0.08 \pm 0.42^{\int, 9}$ & $1.01 \pm 2.09^{9}$ & $3.99 \pm 3.53$ & $<0.001$ \\
\hline Pain interference index & $0.6 \pm 1.5^{\int, 9}$ & $6.3 \pm 6.0^{5}$ & $17.3 \pm 7.3$ & $<0.001$ \\
\hline \multicolumn{5}{|l|}{ MOS-SS ${ }^{\dagger}$} \\
\hline Sleep quantity & $5.08 \pm 1.26^{\int, 9}$ & $3.54 \pm 1.76$ & $3.67 \pm 1.88$ & $<0.001$ \\
\hline Respiratory problem during sleep & $5.96 \pm 0.23^{\int, 9}$ & $5.67 \pm 0.83$ & $5.39 \pm 1.23$ & $<0.001$ \\
\hline Sleep initiation problem & $5.46 \pm 1.10^{\int, 9}$ & $3.95 \pm 1.94$ & $4.00 \pm 1.94$ & $<0.001$ \\
\hline Sleep maintenance problem & $5.41 \pm 1.12^{\int, 9}$ & $3.92 \pm 1.81$ & $4.05 \pm 1.85$ & $<0.001$ \\
\hline Somnolence & $5.77 \pm 0.64^{\int, 9}$ & $5.09 \pm 1.32$ & $4.92 \pm 1.40$ & $<0.001$ \\
\hline Sleep adequacy & $5.29 \pm 1.17 \int, 9$ & $3.84 \pm 1.79$ & $4.00 \pm 1.83$ & $<0.001$ \\
\hline Sleep problem index & $33.0 \pm 3.1^{\int, 9}$ & $26.0 \pm 6.3$ & $26.0 \pm 7.2$ & \\
\hline \multicolumn{5}{|l|}{$\mathrm{EQ}-5 \mathrm{D}^{\S}$} \\
\hline Mobility & $1.07 \pm 0.25^{9}$ & $1.26 \pm 0.45^{9}$ & $1.80 \pm 0.50$ & $<0.001$ \\
\hline Self-care & $1.01 \pm 0.13^{g}$ & $1.09 \pm 0.30^{9}$ & $1.33 \pm 0.54$ & $<0.001$ \\
\hline Usual activity & $1.03 \pm 0.17^{9}$ & $1.21 \pm 0.43^{g}$ & $1.76 \pm 0.55$ & $<0.001$ \\
\hline Pain discomfort & $1.08 \pm 0.29$ & $1.51 \pm 0.53^{g}$ & $2.17 \pm 0.51$ & $<0.001$ \\
\hline Anxiety/depression & $1.11 \pm 0.31^{g}$ & $1.40 \pm 0.51^{g}$ & $1.79 \pm 0.67$ & $<0.001$ \\
\hline EQ-5D index ${ }^{\S}$ & $5.3 \pm 0.7^{9}$ & $6.5 \pm 1.4^{5}$ & $8.8 \pm 1.8$ & $<0.001$ \\
\hline EQ-5D VAS & $81.8 \pm 9.6^{\int, 9}$ & $65.9 \pm 16.1^{9}$ & $51.4 \pm 19.3$ & $<0.001$ \\
\hline
\end{tabular}


TABLe 1: Continued.

\begin{tabular}{lcccc}
\hline Variable & $\begin{array}{l}\text { Cluster 1 } \\
(n=448)\end{array}$ & $\begin{array}{l}\text { Cluster 2 } \\
(n=562)\end{array}$ & $\begin{array}{l}\text { Cluster 3 } \\
(n=328)\end{array}$ \\
\hline Medications for DPN & & & $P$ value \\
$\quad$ None & $164(36.6)$ & $191(34.0)$ & $111(33.8)$ \\
Antidepressants & $30(6.7)^{\int, 9}$ & $68(12.1)^{9}$ & $33(10.1)$ & 0.625 \\
Anticonvulsants & $47(10.5)^{\int, 9}$ & $81(14.4)^{9}$ & 0.016 \\
$\alpha$-Lipoic acid & $107(23.9)^{\int, 9}$ & $116(20.6)$ & $54(16.5)$ & $22.0)$ \\
$\gamma$-Linoleic acid & $34(7.6)$ & $33(5.9)$ & 0.001 \\
Others & $83(18.5)$ & $102(18.2)$ & $54(16.5)$ & 0.351 \\
\hline
\end{tabular}

Data are expressed as means \pm SD for continuous variables and frequency (\%) for categorical variables. * Items were derived from the BPI-SF. A 0-10 numeric rating scale was anchored at 0 for "no pain" and 10 for "pain as bad as you can imagine." "Item response on a 6-point scale ranging from 1 for "all of the time" to 6 for "none of the time;" dimensions of sleep quantity, "get the amount of sleep you needed;" and sleep adequacy, "get enough sleep to feel rested upon waking in the morning" were calculated backwards. "Items were from three levels indicating "no problem" (or 1), "some problems" (or 2), and "severe problems" (or 3), and EQ-5D index was the sum of scores of 5 dimensions. ${ }^{*}$ Values from 0 to 100 , where 0 represents the worst imaginable health state and 100 represents the best imaginable health state. ${ }^{\int} P<0.05$ versus $\leq$ cluster 2 and ${ }^{9} P<0.05$ versus cluster 3 . OHA: oral hypoglycemic agent(s); BMI: body mass index; FPG: fasting plasma glucose; MNSI: Michigan Neuropathy Screening Instrument questionnaire; MOS-SS: medical outcomes study sleep scale; EQ-5D: EuroQol, 5-dimensions; VAS: visual analog scale.

in patients with DPN in Korea is $43.1 \%$, and pain is significantly associated with daily life, quality of sleep, and life in patients with diabetic neuropathy [3]. These have made recent treatments and clinical trials for DPN failed to show efficacy in terms of patient outcomes or quality of life (QOL) in patients with DPN $[2,4]$.

The aim of this study was to cluster subgroups of DPN patients according to a composite of sensory symptoms and the clinical impacts on pain severity, sleep disturbance, QOL, and their relations to intensities of patterns of symptoms identified by factor analysis.

\section{Methods}

2.1. Subjects and Methods. Data from a previous crosssectional observational study conducted on patients with DPN $(n=1338)$ in 2010 were used. The study design, methods used to collect the clinical and laboratory data, and the definitions for diabetes and comorbidities (hypertension, dyslipidemia, obesity, retinopathy, and nephropathy) were described previously $[1,3]$. We made the diagnosis of DPN based on (1) the medical records if the date of DPN and reasons of diagnosis were clearly described (typical symptom, signs, or both) by attending physician (already diagnosed, $n=1073$ ) or (2) abnormal results in both Michigan Neuropathy Screening Instrument (MNSI) scoring $(\geq 3)$ and $10 \mathrm{~g}$ monofilament (MF) test ( 2 out of 10 sites) in all studied patients by trained investigator (newly diagnosed, $n=265$ ). MNSI and $10 \mathrm{~g}$ MF test seems to be a clinically relevant and convenient method in clinical practice and recommended as simple diagnostic methods $[1,2]$. At each visit, patients completed self-reported questionnaires, including the modified Korean version of Brief Pain Inventory-Short Form (BPI-SF), with pain severity and interference scales related to their pain or discomfort in the legs or hands; the medical outcomes study (MOS) sleep scale to measure overall sleep quality using a sleep problem index (SPI); the Korean version of the EuroQOL (EQ-5D) with a standardized five-item measure of health profiles; and a visual analog scale (VAS) to assess the current health state. Medications for treatment of DPN at time of study were classified by antidepressants (duloxetine, tricyclic antidepressants), anticonvulsants (pregabalin, gabapentin), $\alpha$-lipoic acid, $\gamma$-linoleic acid, and others (opioid, local preparation, and vasodilators).

2.2. Statistical Analysis. The hierarchical cluster analysis incorporated scores from the following scales: MNSI (total score, 13) $[3,5]$; BPI-SF (a 0-10 numerical scale used to measure four items of pain severity, where $0=$ "no pain" and $10=$ "pain as bad as you can imagine" for each severity level ([worst, least, average, and current pain]; total score, 40) $[3,6]$; MOS sleep scale (a six-point scale ranging from 1 for "all of the time" to 6 for "none of the time;" the dimensions of sleep quantity ["get the amount of sleep you needed"] and sleep adequacy ["get enough sleep to feel rested upon waking in the morning"] were calculated backwards, for a total score of 36) $[7,8]$; and the EQ-5D (five items with three levels indicating "no problem" (1), "some problems" (2), and "severe problems" (3), for a total score of 15) [9]. The pseudo $t^{2}$ statistic was used to derive the optimal number of clusters. The number of clusters was determined through a step-down method to the final 3 clusters.

The exploratory factor analysis was performed to identify neuropathic symptom patterns using 12 of 15 items of MNSI self-administered questionnaire (excluding 3 questions: questions number 4 and number 10 were considered to be impaired circulation and general asthenia, respectively; question number 9 was not a questionnaire for neuropathic symptom but diagnosis of DPN). Principal component analysis was used to extract summary factors, and we extracted the factors with eigenvalues $\geq 1$. The varimax rotation method was performed to simplify the interpretations of summary factors; one symptom was considered to be loaded on a factor if its factor loading was $\geq 0.40$. Finally, the label of a summary factor was denominated according to the loaded symptoms on a specific factor. Descriptive statistical analyses were performed using SPSS Statistics for Windows, version 
TABLE 2: Comparison of the demographic and clinical characteristics and the clinical impacts of diabetic peripheral neuropathy on pain, sleep, and quality of life in three clustered groups in already diagnosed patients $(n=1073)$.

\begin{tabular}{|c|c|c|c|c|}
\hline Variable & $\begin{array}{l}\text { Cluster } 1 \\
(n=542)\end{array}$ & $\begin{array}{l}\text { Cluster } 2 \\
(n=407)\end{array}$ & $\begin{array}{l}\text { Cluster } 3 \\
(n=124)\end{array}$ & $P$ value \\
\hline Age, years & $61.2 \pm 10.7$ & $62.7 \pm 10.9$ & $60.3 \pm 11.2$ & 0.030 \\
\hline Female, $n(\%)$ & $267(49.3)$ & $245(60.2)$ & $79(63.7)$ & $<0.001$ \\
\hline Diabetes treatment, $n(\%)$ & & & & $<0.001$ \\
\hline Diet and exercise & $12(2.2)$ & $4(1.0)$ & $0(0.0)$ & \\
\hline OHA & $347(64.0)$ & $203(49.9)$ & $49(39.5)$ & \\
\hline Insulin & $54(10.0)$ & $67(16.5)$ & $26(21.0)$ & \\
\hline Insulin and OHA & $129(23.8)$ & $133(32.7)$ & $49(39.5)$ & \\
\hline BMI, $\mathrm{kg} / \mathrm{m}^{2}$ & $24.8 \pm 3.4$ & $25.0 \pm 3.7$ & $25.5 \pm 3.8$ & 0.165 \\
\hline $\mathrm{FPG}, \mathrm{mg} / \mathrm{dL}$ & $141.6 \pm 49.8$ & $141.7 \pm 52.0$ & $164.2 \pm 89.6$ & 0.001 \\
\hline HbA1c, \% & $7.6 \pm 1.5$ & $7.7 \pm 1.5$ & $8.3 \pm 2.1$ & $<0.001$ \\
\hline $\mathrm{HbAlc}, \mathrm{mmol} / \mathrm{mol}$ & $60.0 \pm 16.6$ & $60.5 \pm 16.4$ & $67.0 \pm 22.5$ & $<0.001$ \\
\hline Hypertension & $339(62.6)$ & $277(68.1)$ & $87(70.2)$ & 0.107 \\
\hline Dyslipidemia & $294(54.2)$ & $217(53.3)$ & $61(49.2)$ & 0.596 \\
\hline Obesity & $42(7.8)$ & $19(4.7)$ & $12(9.7)$ & 0.070 \\
\hline Diabetic retinopathy, $n(\%)$ & $162(29.9)$ & $155(38.1)$ & $55(44.4)$ & 0.002 \\
\hline Diabetic nephropathy & $109(20.1)$ & $112(27.5)$ & $33(26.6)$ & 0.021 \\
\hline MNSI score & $1.8 \pm 1.6$ & $3.6 \pm 1.9$ & $5.8 \pm 2.4$ & $<0.001$ \\
\hline \multicolumn{5}{|l|}{ Pain severity items } \\
\hline Worst & $0.6 \pm 1.4$ & $4.9 \pm 2.8$ & $7.8 \pm 1.9$ & $<0.001$ \\
\hline Weakest & $0.1 \pm 0.3$ & $1.2 \pm 1.6$ & $2.8 \pm 2.1$ & $<0.001$ \\
\hline Average & $0.3 \pm 0.7$ & $2.8 \pm 1.9$ & $5.4 \pm 1.8$ & $<0.001$ \\
\hline \multicolumn{5}{|l|}{ Pain interference items* } \\
\hline General activity & $0.2 \pm 0.7$ & $2.2 \pm 2.8$ & $6.2 \pm 2.8$ & $<0.001$ \\
\hline Mood & $0.3 \pm 1.1$ & $3.0 \pm 3.0$ & $7.0 \pm 2.2$ & $<0.001$ \\
\hline Walking & $0.1 \pm 0.7$ & $2.1 \pm 2.9$ & $5.7 \pm 3.1$ & $<0.001$ \\
\hline Normal work & $0.1 \pm 0.7$ & $2.0 \pm 2.8$ & $6.0 \pm 3.0$ & $<0.001$ \\
\hline Relationship & $0.1 \pm 0.5$ & $1.0 \pm 2.1$ & $4.2 \pm 3.4$ & $<0.001$ \\
\hline Sleep & $0.2 \pm 0.9$ & $2.2 \pm 3.0$ & $5.9 \pm 3.3$ & $<0.001$ \\
\hline Enjoyment of life & $0.1 \pm 0.6$ & $1.7 \pm 2.6$ & $5.4 \pm 3.3$ & $<0.001$ \\
\hline Pain interference index & $0.9 \pm 2.3$ & $10.4 \pm 6.5$ & $20.4 \pm 6.2$ & $<0.001$ \\
\hline \multicolumn{5}{|l|}{ 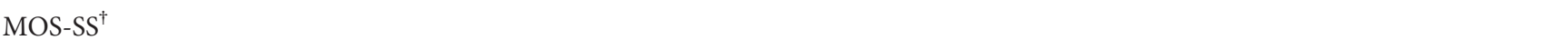 } \\
\hline Sleep quantity & $4.8 \pm 1.5$ & $3.7 \pm 1.8$ & $2.5 \pm 1.5$ & $<0.001$ \\
\hline Respiratory problem during sleep & $5.9 \pm 0.4$ & $5.7 \pm 0.8$ & $5.0 \pm 1.5$ & $<0.001$ \\
\hline Sleep initiation problem & $5.2 \pm 1.4$ & $4.1 \pm 1.9$ & $3.1 \pm 1.8$ & $<0.001$ \\
\hline Sleep maintenance problem & $5.1 \pm 1.4$ & $4.1 \pm 1.8$ & $3.3 \pm 1.8$ & $<0.001$ \\
\hline Somnolence & $5.7 \pm 0.8$ & $5.1 \pm 1.3$ & $4.5 \pm 1.5$ & $<0.001$ \\
\hline Sleep adequacy & $5.0 \pm 1.4$ & $4.0 \pm 1.8$ & $3.0 \pm 1.8$ & $<0.001$ \\
\hline Sleep problem index & $31.7 \pm 4.6$ & $26.6 \pm 6.2$ & $21.4 \pm 6.2$ & $<0.001$ \\
\hline \multicolumn{5}{|l|}{ EQ-5D ${ }^{\S}$} \\
\hline Mobility & $1.1 \pm 0.3$ & $1.4 \pm 0.5$ & $1.9 \pm 0.5$ & $<0.001$ \\
\hline Self-care & $1.0 \pm 0.1$ & $1.1 \pm 0.4$ & $1.4 \pm 0.5$ & $<0.001$ \\
\hline Usual activity & $1.0 \pm 0.2$ & $1.3 \pm 0.5$ & $2.0 \pm 0.5$ & $<0.001$ \\
\hline Pain discomfort & $1.1 \pm 0.3$ & $1.7 \pm 0.5$ & $2.4 \pm 0.5$ & $<0.001$ \\
\hline Anxiety/depression & $1.2 \pm 0.4$ & $1.4 \pm 0.6$ & $2.1 \pm 0.7$ & $<0.001$ \\
\hline EQ-5D index ${ }^{\S}$ & $5.4 \pm 0.8$ & $7.0 \pm 1.5$ & $9.7 \pm 1.5$ & $<0.001$ \\
\hline EQ-5D VAS & $77.9 \pm 12.8$ & $64.0 \pm 16.1$ & $44.2 \pm 19.0$ & $<0.001$ \\
\hline
\end{tabular}


TABLE 2: Continued.

\begin{tabular}{|c|c|c|c|c|}
\hline Variable & $\begin{array}{l}\text { Cluster } 1 \\
(n=542)\end{array}$ & $\begin{array}{l}\text { Cluster } 2 \\
(n=407)\end{array}$ & $\begin{array}{l}\text { Cluster } 3 \\
(n=124)\end{array}$ & $P$ value \\
\hline \multicolumn{5}{|c|}{ Medications for DPN } \\
\hline None & $142(26.2)$ & $79(19.4)$ & $21(16.9)$ & 0.013 \\
\hline Antidepressants & $50(9.2)$ & $60(14.7)$ & $17(13.7)$ & 0.027 \\
\hline Anticonvulsants & $67(12.4)$ & $99(24.3)$ & $31(25.0)$ & $<0.001$ \\
\hline$\alpha$-Lipoic acid & $148(27.3)$ & $91(22.4)$ & $27(21.8)$ & 0.154 \\
\hline$\gamma$-Linoleic acid & $47(8.7)$ & $29(7.1)$ & $14(11.3)$ & 0.323 \\
\hline Others & $113(20.9)$ & $80(19.7)$ & $26(21.0)$ & 0.891 \\
\hline
\end{tabular}

Data are expressed as means \pm SD for continuous variables and frequency (\%) for categorical variables. ${ }^{*}$ Items were derived from the BPI-SF. A $0-10$ numeric rating scale was anchored at 0 for "no pain" and 10 for "pain as bad as you can imagine." "Item response on a 6-point scale ranging from 1 for "all of the time" to 6 for "none of the time;" dimensions of sleep quantity, "get the amount of sleep you needed;" and sleep adequacy, "get enough sleep to feel rested upon waking in the morning" were calculated backwards. "Items were from three levels indicating "no problem" (or 1), "some problems" (or 2), and "severe problems" (or 3), and EQ-5D index was the sum of scores of 5 dimensions. ${ }^{*}$ Values from 0 to 100 , where 0 represents the worst imaginable health state and 100 represents the best imaginable health state. OHA: oral hypoglycemic agent(s); BMI: body mass index; FPG: fasting plasma glucose; MNSI: Michigan Neuropathy Screening Instrument questionnaire; MOS-SS: medical outcomes study sleep scale; EQ-5D: EuroQol, 5-dimensions; VAS: visual analog scale.

18.0 (SPSS Inc., Chicago, IL, USA) and SAS 9.4 (SAS Institute, Cary, NC, USA); significance was set at $P<0.05$. Continuous variables are presented as means \pm SDs and categorical data as frequencies and percentages and compared between clusters by ANOVA tests or chi-square or Fisher's exact tests.

\section{Results}

3.1. Cluster Analysis Identified 3 Groups in Patients with $D P N$. The mean patient age was $62.3 \pm 10.7$ years; $55.7 \%$ of the patients were women, with a mean body mass index of $25.0 \pm 3.6 \mathrm{~kg} / \mathrm{m}^{2}$. Most patients (56.9\%) had taken oral hypoglycemic agent(s) for their diabetes. With cluster analysis to determine constellations of the entire patients with DPN, three clusters were identified (Table 1). Patients in cluster $3(n=328$ [24.5\%], "severe symptoms and decreased QOL" were characterized by higher HbAlc levels, more prevalent retinopathy and nephropathy, a higher pain level, and more severe mental and physical impairments compared with patients in cluster $2(n=$ 562 [42.0\%], "moderate symptoms and disturbed sleep") and cluster 1 ( $n=448$ [33.5\%], "asymptomatic"), as indicated by the mean comorbidity scores for all examined areas. Patients in cluster 2 had moderate pain levels but disturbed sleep patterns comparable to those of the patients in cluster 3. Patients in cluster 1 had mild pain and nearly normal sleep patterns and QOL compared with patients in clusters 2 and 3 . While the pain interference index increased from clusters 1 to 3 , SPI was significantly compromised in clusters 2 and 3 compared with cluster 1. The EQ-5D index was the lowest in cluster 3, and the EQ-5D VAS score decreased significantly from clusters 1 to 3 .

When we performed cluster analysis in subgroups according to either already or newly diagnosed to DPN at time of study, three clustered groups were found in each subgroup. And the demographic and clinical characteristics in each subgroup analyses were showed similar trends as those in the entire population (Tables 2 and 3), while mean value of $\mathrm{HbAlc}$ and prevalence of retinopathy and nephropathy were statistically different along the cluster 1 to 3 in already-diagnosed patients but not in newly diagnosed patients (Tables 2 and 3).

At time of study, $65.1 \%(n=872), 77.5 \%(n=831)$, and $15.7 \%(n=41)$, respectively, in the entire, already, and newly diagnosed patients were prescribed medication(s) for their DPN. While patients taking antidepressants and anticonvulsants were more prevalent in cluster 2 and 3, respectively, compared to cluster 1 , those taking $\alpha$-lipoic acid were more prevalent in cluster 1 compared to cluster 2 and 3 (Tables 1 and 2).

3.2. Factor Analysis Revealed Three Distinct Symptom Patterns in Patients with DPN. Three Eigenvalues were greater than unity $(\geq 1.017)$ and this determined three factors computed in the entire patients. Table 4 presented the results of factor analysis which explained $43.4 \%$ of the total variance in the 1338 patients with DPN. Factor 1 ("painful") included number 1 ("are your legs and/or feet numb?"), number 2 (“do you ever have any burning pain in your legs and/or feet?"), number 3 ("are your feet too sensitive to touch?"), number 5 ("do you ever have any prickling feelings in your legs or feet?"), and number 6 ("does it hurt when the bed covers touch your skin?"), and number 11("are your symptoms worse at night?"). Factor 2 ("insensate") was number 7 ("when you get into the tub or shower, are you able to tell the hot water from the cold water?") and number 13 ("are you able to sense your feet when you walk?"), and factor 3 ("ulcerative") was number 8 ("have you ever had an open sore on your foot?"), number 12 ("do your legs hurt when you walk?"), and number 15 ("have you ever had an amputation?"). The total variance for each factor was $19.8 \%, 12.1 \%$, and $11.5 \%$ from factor 1,2 , and 3 , respectively. The factorability was proved by a Kaiser-Meyer-Olkin index that was 0.749 and the result of Bartlett's test of sphericity indicated no identity $(P<0.001)$.

3.3. Frequency of Symptom Patterns according to 3 Cluster Groups of DPN. Figure 1 shows the frequencies of symptoms 
TABLE 3: Comparison of the demographic and clinical characteristics and the clinical impacts of diabetic peripheral neuropathy on pain, sleep, and quality of life in three clustered groups in newly diagnosed patients $(n=265)$.

\begin{tabular}{|c|c|c|c|c|}
\hline Variable & $\begin{array}{l}\text { Cluster 1 } \\
(n=542)\end{array}$ & $\begin{array}{l}\text { Cluster } 2 \\
(n=407)\end{array}$ & $\begin{array}{l}\text { Cluster } 3 \\
(n=124)\end{array}$ & $P$ value \\
\hline Age, years & $64.3 \pm 10.0$ & $66.1 \pm 9.7$ & $64.6 \pm 9.5$ & 0.447 \\
\hline Female, $n(\%)$ & $89.0(58.6)$ & $33.0(48.5)$ & $32.0(71.1)$ & 0.058 \\
\hline Diabetes treatment, $n(\%)$ & & & & 0.008 \\
\hline Diet and exercise & $6(4.0)$ & $1(1.5)$ & $1(2.2)$ & \\
\hline OHA & $105(69.1)$ & $34(50.0)$ & $23(51.1)$ & \\
\hline Insulin & $14(9.2)$ & $18(26.5)$ & $7(15.6)$ & \\
\hline Insulin and $\mathrm{OHA}$ & $27(17.8)$ & $15(22.1)$ & $14(31.1)$ & \\
\hline BMI, $\mathrm{kg} / \mathrm{m}^{2}$ & $25.4 \pm 3.5$ & $24.5 \pm 3.8$ & $25.6 \pm 4.2$ & 0.276 \\
\hline $\mathrm{FPG}, \mathrm{mg} / \mathrm{dL}$ & $132.4 \pm 41.3$ & $147.6 \pm 51.6$ & $141.0 \pm 76.1$ & 0.260 \\
\hline HbAlc, \% & $7.5 \pm 1.4$ & $7.9 \pm 1.7$ & $9.1 \pm 9.8$ & 0.121 \\
\hline $\mathrm{HbAlc}, \mathrm{mmol} / \mathrm{mol}$ & $59.0 \pm 15.1$ & $62.8 \pm 18.1$ & $76.3 \pm 106.7$ & 0.121 \\
\hline Hypertension & $101(66.5)$ & $48(70.6)$ & $27(60.0)$ & 0.506 \\
\hline Dyslipidemia & $76(50.0)$ & $36(52.9)$ & $20(44.4)$ & 0.675 \\
\hline Obesity & $4(2.6)$ & $0(0.0)$ & $3(6.7)$ & 0.096 \\
\hline Diabetic retinopathy, $n(\%)$ & $27(17.8)$ & $18(26.5)$ & $8(17.8)$ & 0.302 \\
\hline Diabetic nephropathy & $25(16.5)$ & $16(23.5)$ & $6(13.3)$ & 0.311 \\
\hline MNSI score & $3.1 \pm 1.2$ & $3.9 \pm 1.2$ & $6.5 \pm 1.9$ & $<0.001$ \\
\hline \multicolumn{5}{|l|}{ Pain severity items } \\
\hline Worst & $2.1 \pm 2.7$ & $5.0 \pm 3.6$ & $7.6 \pm 2.5$ & $<0.001$ \\
\hline Weakest & $0.4 \pm 0.8$ & $1.3 \pm 1.6$ & $2.9 \pm 2.2$ & $<0.001$ \\
\hline Average & $1.1 \pm 1.5$ & $3.1 \pm 2.5$ & $5.1 \pm 2.3$ & $<0.001$ \\
\hline \multicolumn{5}{|l|}{ Pain interference items* } \\
\hline General activity & $0.6 \pm 1.5$ & $3.2 \pm 3.2$ & $6.4 \pm 2.9$ & $<0.001$ \\
\hline Mood & $1.1 \pm 2.0$ & $3.7 \pm 3.2$ & $6.8 \pm 2.9$ & $<0.001$ \\
\hline Walking & $0.6 \pm 1.5$ & $3.0 \pm 3.2$ & $6.1 \pm 3.2$ & $<0.001$ \\
\hline Normal work & $0.7 \pm 1.5$ & $2.9 \pm 3.1$ & $6.1 \pm 3.3$ & $<0.001$ \\
\hline Relationship & $0.3 \pm 1.0$ & $1.7 \pm 2.5$ & $4.8 \pm 3.7$ & $<0.001$ \\
\hline Sleep & $0.8 \pm 1.8$ & $2.1 \pm 3.0$ & $5.8 \pm 3.4$ & $<0.001$ \\
\hline Enjoyment of life & $0.5 \pm 1.3$ & $2.3 \pm 3.1$ & $5.7 \pm 3.7$ & $<0.001$ \\
\hline Pain interference index & $4.0 \pm 5.1$ & $10.8 \pm 7.9$ & $19.4 \pm 7.7$ & $<0.001$ \\
\hline \multicolumn{5}{|l|}{ MOS-SS ${ }^{\dagger}$} \\
\hline Sleep quantity & $4.3 \pm 1.7$ & $4.2 \pm 1.8$ & $2.7 \pm 1.7$ & $<0.001$ \\
\hline Respiratory problem during sleep & $5.8 \pm 0.7$ & $5.8 \pm 0.6$ & $4.8 \pm 1.7$ & $<0.001$ \\
\hline Sleep initiation problem & $4.6 \pm 1.8$ & $4.5 \pm 1.7$ & $2.6 \pm 1.7$ & $<0.001$ \\
\hline Sleep maintenance problem & $4.4 \pm 1.8$ & $4.7 \pm 1.6$ & $2.7 \pm 1.8$ & $<0.001$ \\
\hline Somnolence & $5.4 \pm 1.0$ & $5.3 \pm 1.1$ & $3.8 \pm 1.7$ & $<0.001$ \\
\hline Sleep adequacy & $4.6 \pm 1.6$ & $4.5 \pm 1.7$ & $2.7 \pm 1.8$ & $<0.001$ \\
\hline Sleep problem index & $29.2 \pm 5.9$ & $28.9 \pm 5.4$ & $19.3 \pm 5.8$ & $<0.001$ \\
\hline \multicolumn{5}{|l|}{$E Q-5 D^{\S}$} \\
\hline Mobility & $1.2 \pm 0.4$ & $1.8 \pm 0.5$ & $2.0 \pm 0.5$ & $<0.001$ \\
\hline Self-care & $1.1 \pm 0.3$ & $1.2 \pm 0.5$ & $1.6 \pm 0.7$ & $<0.001$ \\
\hline Usual activity & $1.1 \pm 0.3$ & $1.7 \pm 0.5$ & $2.0 \pm 0.5$ & $<0.001$ \\
\hline Pain discomfort & $1.3 \pm 0.5$ & $2.0 \pm 0.4$ & $2.4 \pm 0.6$ & $<0.001$ \\
\hline Anxiety/depression & $1.3 \pm 0.5$ & $1.6 \pm 0.5$ & $2.0 \pm 0.6$ & $<0.001$ \\
\hline EQ-5D index ${ }^{\S}$ & $6.0 \pm 1.4$ & $8.2 \pm 1.2$ & $10.0 \pm 1.9$ & $<0.001$ \\
\hline EQ-5D VAS ${ }^{\ddagger}$ & $74.2 \pm 14.1$ & $53.9 \pm 16.7$ & $41.4 \pm 21.2$ & $<0.001$ \\
\hline
\end{tabular}


TABLe 3: Continued.

\begin{tabular}{|c|c|c|c|c|}
\hline Variable & $\begin{array}{l}\text { Cluster } 1 \\
(n=542)\end{array}$ & $\begin{array}{l}\text { Cluster } 2 \\
(n=407)\end{array}$ & $\begin{array}{l}\text { Cluster } 3 \\
(n=124)\end{array}$ & $P$ value \\
\hline \multicolumn{5}{|c|}{ Medications for DPN } \\
\hline None & $133(87.5)$ & $55(80.9)$ & $36(80.0)$ & 0.298 \\
\hline Antidepressants & $1(0.7)$ & $3(4.4)$ & $0(0.0)$ & 0.071 \\
\hline Anticonvulsants & $1(0.7)$ & $1(1.5)$ & $1(2.2)$ & 0.653 \\
\hline$\alpha$-Lipoic acid & $6(4.0)$ & $4(5.9)$ & $1(2.2)$ & 0.622 \\
\hline$\gamma$-Linoleic acid & $1(0.7)$ & $1(1.5)$ & $2(4.4)$ & 0.187 \\
\hline Others & $10(6.6)$ & $5(7.4)$ & $5(11.1)$ & 0.598 \\
\hline
\end{tabular}

Data are expressed as means \pm SD for continuous variables and frequency (\%) for categorical variables. * Items were derived from the BPI-SF. A 0-10 numeric rating scale was anchored at 0 for "no pain" and 10 for "pain as bad as you can imagine." "Item response on a 6-point scale ranging from 1 for "all of the time" to 6 for "none of the time;" dimensions of sleep quantity, "get the amount of sleep you needed;" and sleep adequacy, "get enough sleep to feel rested upon waking in the morning" were calculated backwards. "Items were from three levels indicating "no problem" (or 1), "some problems" (or 2), and "severe problems" (or 3), and EQ-5D index was the sum of scores of 5 dimensions. "Values from 0 to 100 , where 0 represents the worst imaginable health state and 100 represent the best imaginable health state. OHA: oral hypoglycemic agent(s); BMI: body mass index; FPG: fasting plasma glucose; MNSI: Michigan Neuropathy Screening Instrument questionnaire; MOS-SS: medical outcomes study sleep scale; EQ-5D: EuroQol, 5-dimensions; VA: visual analog scale.

TABLE 4: Varimax rotated factor loadings for Michigan Neuropathy Screening Instrument (MNSI) questionnaire items.

\begin{tabular}{|c|c|c|c|}
\hline MNSI items & $\begin{array}{c}\text { Factor } \\
1 \\
\end{array}$ & $\begin{array}{c}\text { Factor } \\
2 \\
\end{array}$ & $\begin{array}{c}\text { Factor } \\
3 \\
\end{array}$ \\
\hline Number 2. Do you ever have any burning pain in your legs and/or feet? & 0.662 & 0.076 & -0.057 \\
\hline Number 11. Are your symptoms worse at night? & 0.648 & -0.003 & -0.030 \\
\hline Number 5 . Do you ever have any prickling feelings in your legs or feet? & 0.609 & 0.014 & 0.158 \\
\hline Number 1. Are your legs and/or feet numb? & 0.566 & -0.068 & 0.125 \\
\hline Number 3. Are your feet too sensitive to touch? & 0.536 & 0.020 & 0.119 \\
\hline Number 6. Does it hurt when the bed covers touch your skin? & 0.410 & 0.351 & 0.037 \\
\hline Number 14 . Is the skin on your feet so dry that it cracks open? & 0.263 & -0.042 & 0.202 \\
\hline Number 13. Are you able to sense your feet when you walk? & -0.058 & 0.769 & 0.063 \\
\hline Number 7. When you get into the tub or shower, are you able to tell the hot water from the cold water? & 0.022 & 0.758 & 0.050 \\
\hline Number 15. Have you ever had an amputation? & -0.122 & -0.021 & 0.781 \\
\hline Number 8 . Have you ever had an open sore on your foot? & 0.195 & 0.173 & 0.654 \\
\hline Number 12. Do your legs hurt when you walk? & 0.334 & 0.010 & 0.394 \\
\hline Variance, $\%$ & 19.8 & 12.1 & 11.5 \\
\hline
\end{tabular}

Factor loadings $\geq 0.40$ are in bold.

represented by results of factor analysis on the MNSI items in the three clustered groups. The symptoms showed a similar distribution pattern but different intensities. "Painful" symptoms were increased in prominence from clusters 1 to 3 (all MNSI items, $P<0.05$, between groups), but "insensate" was the prominent symptom that differentiated cluster 3 (highly prominent) from clusters 1 and $2(P<0.05)$. "Insensate" did not differ among the clusters 1 and 2. "Ulcerative" was significantly different between cluster 1 and 2 and cluster 3 . However, MNSI number 15 asking history of foot ulcer ("have you ever had an amputation?") was not different between cluster 1 and 2, but those in cluster 3 were significantly more frequent in cluster 3 compared to cluster 1 and 2 .

\section{Discussion}

In the current study, patients with DPN were divided into three groups by combining subjective DPN symptoms with the clinical impacts of DPN on pain, sleep, and QOL using cluster analysis in the entire patients as well as in separated analyses by diagnostic methods for DPN. Patients in cluster 3 were associated with the greatest pain intensity and the lowest QOL, whereas patients in cluster 2 were associated with moderate pain intensity but a high degree of sleep impairment. The higher level of $\mathrm{HbAlc}$ and proportion of patients taking insulin with or without oral hypoglycemic agent(s) in cluster 3 showed simultaneous relationships between poorly controlled glycemia and other microvascular complications: retinopathy and nephropathy. While the frequency distributions of each symptom on the MNSI were similar, more patients in cluster 3 than in clusters 1 and 2 exhibited high pain intensities and these tendencies were consistent through patterns of symptom. These results are consistent with previous observations in a large cohort of patients with the same etiology, in that patients exhibiting heterogeneous symptoms could be divided into 


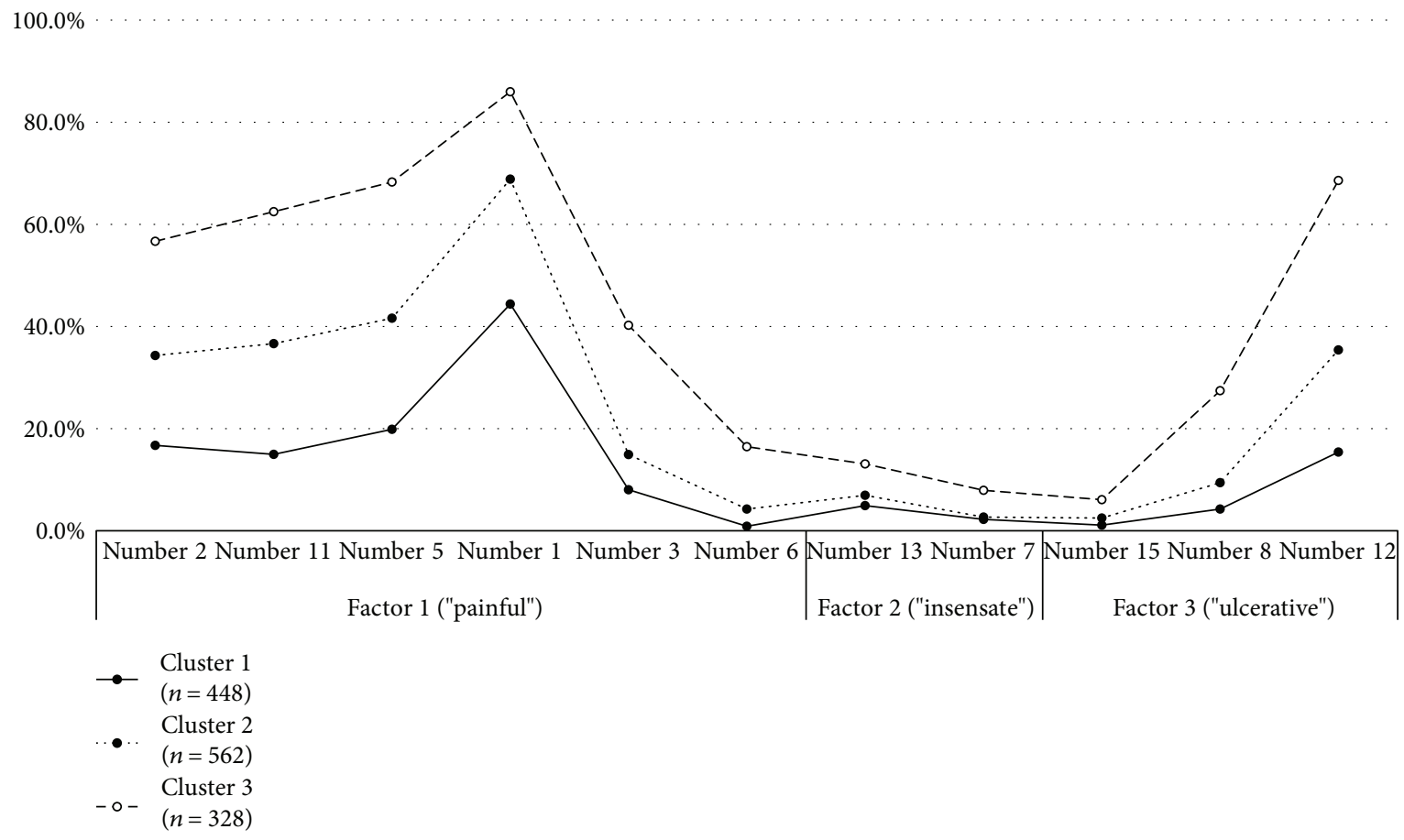

FIgURE 1: The frequency (\%) distribution of symptoms on the MNSI questionnaire among the three cluster according to three subgroups of symptom patterns. MNSI number 14 (“is the skin on your feet so dry that it cracks open?") was deleted in this figure because factor loading was $<0.40$ in Table 2.

several subgroups according to neuropathy-related symptom profiles $[10,11]$.

In this study, cluster 3 had prominent intensities across the subgroup of symptom patterns and, in particular, "insensate" and some items of "ulcerative" were differentiated from cluster 1 and 2 . These findings are consistent with that symptoms of DPN are heterogeneous and vary widely, depending on patterns of nerve damage by different size and function. And it is suggested that pain is progressively reduced after a long-lasting painful episode to be insensible to cold, warm, and painful stimuli [12]. However, subjective symptoms are not clearly divided but even confused in patients with DPN across the duration of DPN, and it does not completely take into account different pathogenesis involving peripheral nerve damage.

In this study, pain intensity seemed to be the most important variable in the differentiation of patients with DPN into the three clusters. In addition, while the level of impaired QOL was important for differentiating cluster 2 from cluster 3 , the level of sleep impairment was for differentiating cluster 1 from cluster 2. It is common for patients with DPN to experience various symptoms at the same time for which one treatment may reduce the severity of some of the symptoms but not all of the symptoms. Recently, validated patientreported outcome measures were developed to estimate the response of patients with DPN to treatment $[10,13]$. However, clinical trials investigating the efficacy of pharmacologic treatments failed to meet their primary outcomes [14], because neuropathy-related symptoms were complex and related to pain as well as psychological and physical performance, sleep quality and quantity, and overall QOL in daily activities $[3,7,15]$. Therefore, a comprehensive approach regarding the impact of DPN on these health-related issues is needed and it is important for physician when dealing with neuropathy-related symptoms in patients with type 2 diabetes to consider not only somatic symptoms but also comorbidities.

Although various measures of the clinical impacts of DPN on daily pain, sleep, and QOL were evaluated in a large number of patients, this study has several limitations. First, the diagnosis of DPN was based on definition used in clinical practice ("possible" to "probable") rather than neurophysiological studies ("confirmed") [2]. However, we thought this detection methods could be acceptable for this population to actual data for prevalence and clinical characteristics of DPN in Korea with this study. Second, the symptoms were based only on the dichromatic responses to MNSI items in this study, compared with other studies using numeric scales on self-rated questionnaires $[12,13]$. Third, the effects of medications on neuropathic symptoms, pain intensity, sleep, and QOL and the difference in treatment at each cluster ( $\alpha$-lipoic acid in cluster 1 , antidepressants in cluster 2 , and anticonvulsants in cluster 3) were not conclusive because of the cross-sectional nature of this study. However, these complementary and exploratory analyses further support the idea that sensory phenotyping might lead to more stratified and individualized treatment in patients with DPN. Finally, how to define the pathophysiology-based differentiation of symptom clustering is not clear, and the causal relationships between comorbidities and the clustered subgroups cannot be explored because of limited cross-sectional observational study designs. We thought this study as a 
preliminary analysis to be a basis for further studies with detailed description and evaluation of symptoms and comorbidities, that is, mood disorder and socioeconomic aspects and various measures for outcomes. Future studies are needed to explore the effects of DPN on pain, sleep disturbance, and impaired QOL.

In conclusion, with cluster and factor analysis, we identified 3 cluster groups based on the sensory symptoms and comorbidities and 3 patterns of sensory symptoms in patients with DPN in Korea. Although, DPN is considered as heterogeneous and complex disease, these comprehensive approaches would endorse subgrouping to individualize the evaluation and treatment of patients with DPN.

\section{Conflicts of Interest}

The authors declare that they have no conflicts of interest.

\section{Acknowledgments}

This work was supported by the 2016 Inje University research grant (Jong Chul Won).

\section{References}

[1] J. Won, H. Kwon, C. Kim et al., "Prevalence and clinical characteristics of diabetic peripheral neuropathy in hospital patients with type 2 diabetes in Korea," Diabetic Medicine, vol. 29, no. 9, pp. e290-e296, 2012.

[2] S. Tesfaye, A. J. Boulton, P. J. Dyck et al., "Diabetic neuropathies: update on definitions, diagnostic criteria, estimation of severity, and treatments," Diabetes Care, vol. 33, no. 10, pp. 2285-2293, 2010.

[3] S. S. Kim, J. C. Won, H. S. Kwon et al., "Prevalence and clinical implications of painful diabetic peripheral neuropathy in type 2 diabetes: results from a nationwide hospitalbased study of diabetic neuropathy in Korea," Diabetes Research and Clinical Practice, vol. 103, no. 3, pp. 522529, 2014.

[4] S. Tesfaye, A. J. Boulton, and A. H. Dickenson, "Mechanisms and management of diabetic painful distal symmetrical polyneuropathy," Diabetes Care, vol. 36, no. 9, pp. 2456-2465, 2013.

[5] R. G. Frykberg, L. A. Lavery, H. Pham, C. Harvey, L. Harkless, and A. Veves, "Role of neuropathy and high foot pressures in diabetic foot ulceration," Diabetes Care, vol. 21, no. 10, pp. 1714-1719, 1998.

[6] D. C. Zelman, M. Gore, E. Dukes, K.-S. Tai, and N. Brandenburg, "Validation of a modified version of the Brief Pain Inventory for painful diabetic peripheral neuropathy," Journal of Pain and Symptom Management, vol. 29, no. 4, pp. 401-410, 2005.

[7] S. Benbow, M. Wallymahmed, and I. MacFarlane, "Diabetic peripheral neuropathy and quality of life," QJM: An International Journal of Medicine, vol. 91, no. 11, pp. 733-737, 1998.

[8] M. K. Vernon, N. A. Brandenburg, J. M. J. Alvir, T. Griesing, and D. A. Revicki, "Reliability, validity, and responsiveness of the daily sleep interference scale among diabetic peripheral neuropathy and postherpetic neuralgia patients," Journal of Pain and Symptom Management, vol. 36, no. 1, pp. 54-68, 2008.
[9] D. Bouhassira, S. Wilhelm, A. Schacht et al., "Neuropathic pain phenotyping as a predictor of treatment response in painful diabetic neuropathy: data from the randomized, doubleblind, COMBO-DN study," Pain, vol. 155, no. 10, pp. 21712179, 2014.

[10] R. Freynhagen, R. Baron, U. Gockel, and T. R. Tölle, "Pain DETECT: a new screening questionnaire to identify neuropathic components in patients with back pain," Current Medical Research and Opinion, vol. 22, no. 10, pp. 19111920, 2006.

[11] C. A. von Hehn, R. Baron, and C. J. Woolf, "Deconstructing the neuropathic pain phenotype to reveal neural mechanisms," Neuron, vol. 73, no. 4, pp. 638-652, 2012.

[12] T. Burns and M. Mauermann, "The evaluation of polyneuropathies," Neurology, vol. 76, no. 7, Supplement 2, pp. S6-S13, 2011.

[13] R. H. Dworkin, D. C. Turk, D. A. Revicki et al., "Development and initial validation of an expanded and revised version of the short-form McGill pain questionnaire (SF-MPQ-2)," Pain, vol. 144, no. 1, pp. 35-42, 2009.

[14] S. Tesfaye, S. Wilhelm, A. Lledo et al., "Duloxetine and pregabalin: high-dose monotherapy or their combination? The "COMBO-DN study"- a multinational, randomized, doubleblind, parallel-group study in patients with diabetic peripheral neuropathic pain," Pain, vol. 154, no. 12, pp. 2616-2625, 2013.

[15] A. J. Boulton, L. Vileikyte, G. Ragnarson-Tennvall, and J. Apelqvist, "The global burden of diabetic foot disease," The Lancet, vol. 366, no. 9498, pp. 1719-1724, 2005. 


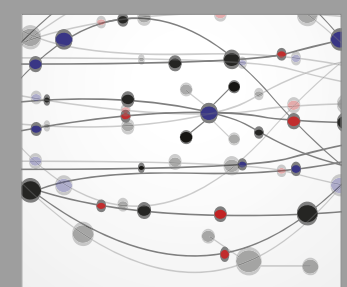

The Scientific World Journal
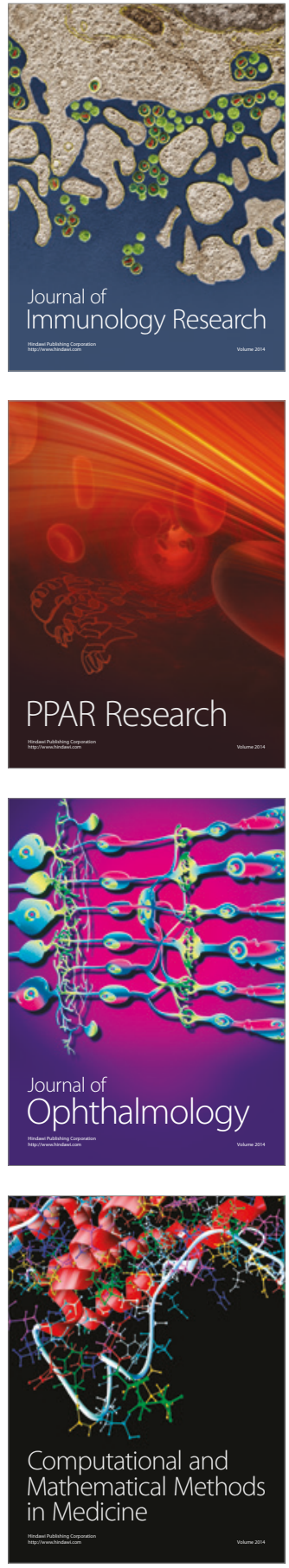

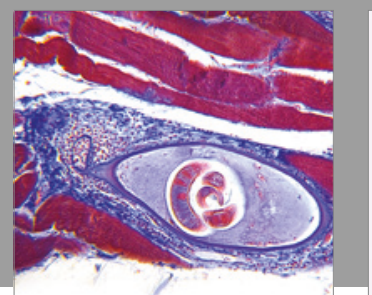

Gastroenterology Research and Practice
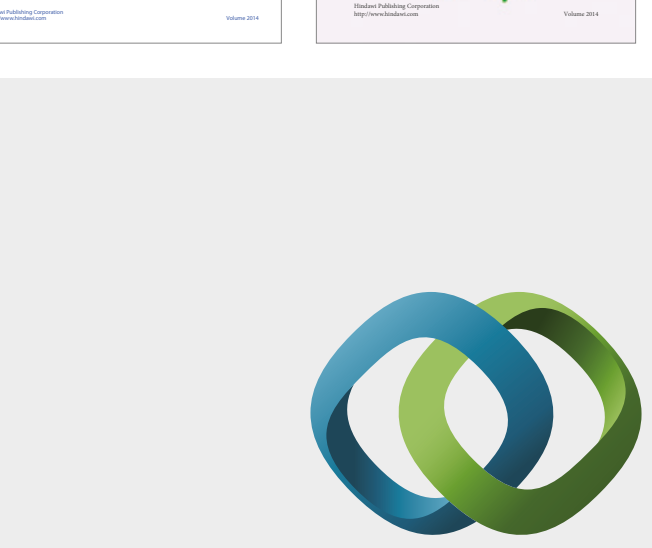

\section{Hindawi}

Submit your manuscripts at

https://www.hindawi.com
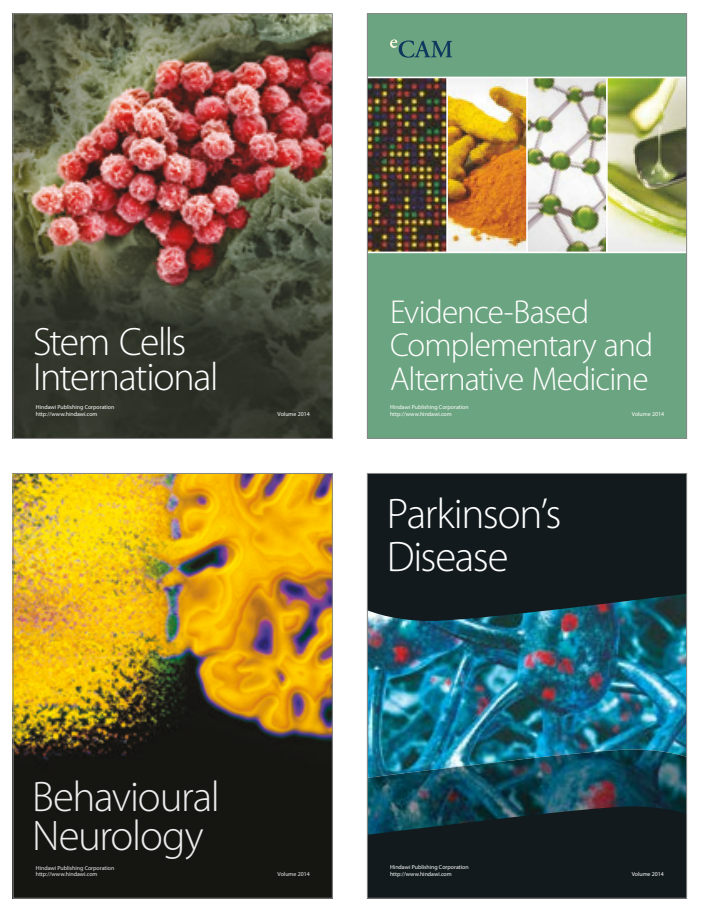
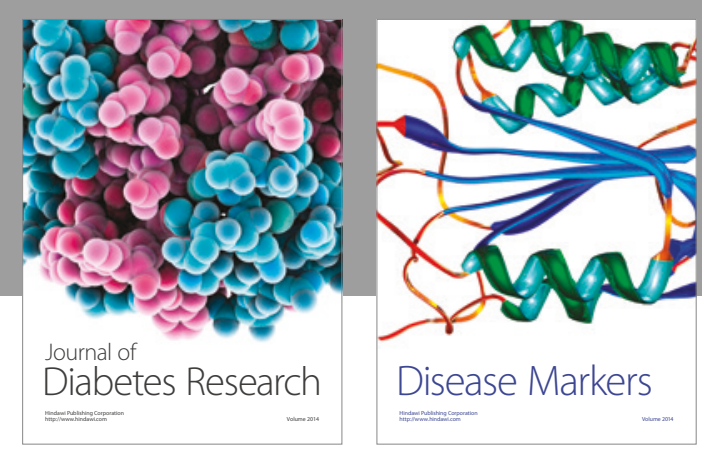

Disease Markers
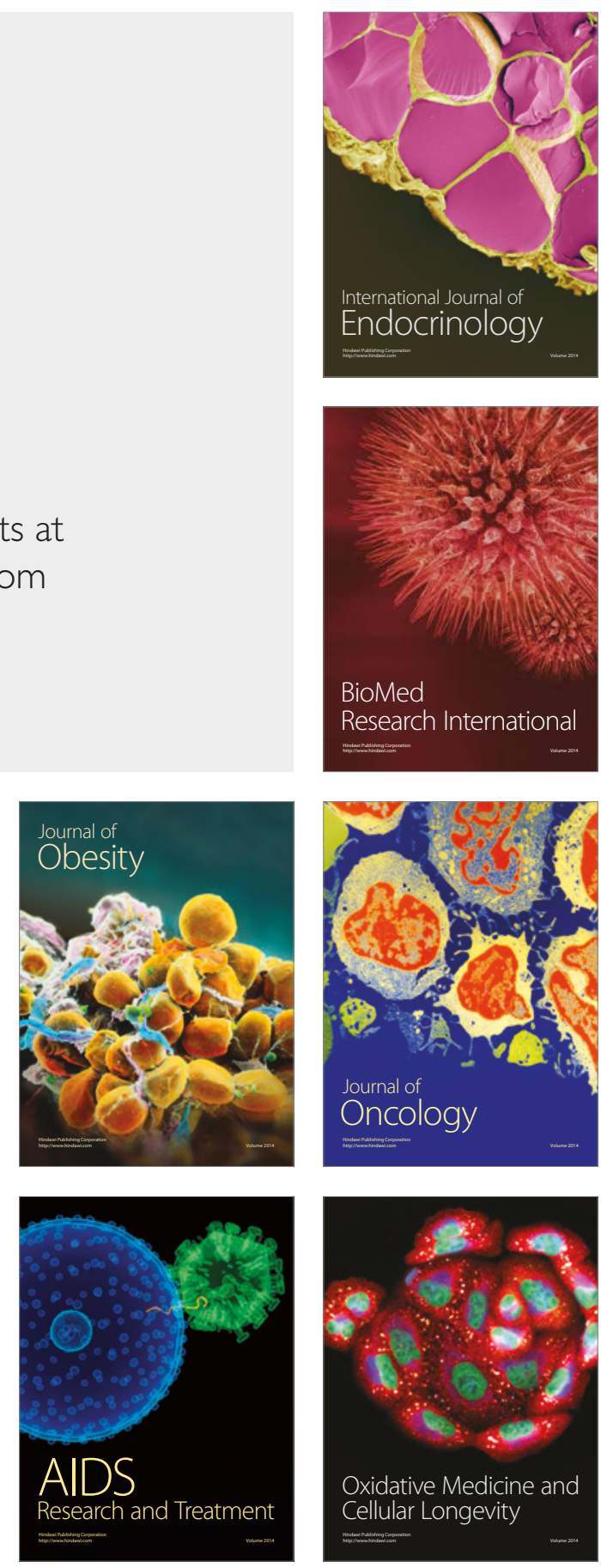